\title{
The Effects of Communication on the Partnership Solution to the Commons
}

\author{
Neil J. Buckley \\ Department of Economics, York University, 4700 Keele Street, \\ Toronto, Ontario, M3J 1P3, Canada \\ Stuart Mestelman and R. Andrew Muller \\ Department of Economics, McMaster University, 1280 Main Street West \\ Hamilton, Ontario, L8S 4M4, Canada \\ Stephan Schott \\ School of Public Policy and Administration, Carleton University, 1125 Colonel By Drive \\ Ottawa, Ontario, KIS 5B6, Canada \\ Jingjing Zhang ${ }^{1}$ \\ Economics Discipline Group, University of Technology Sydney, \\ PO Box 123, Broadway NSW 2007 Sydney, Australia
}

\begin{abstract}
Organizing individual appropriators into output sharing groups has been found to effectively solve the tragedy of the commons problem. We experimentally investigate the robustness of this solution by introducing different channels of communication that naturally arise from group competitions. In the absence of communication, we confirm that output sharing can introduce sufficient free riding to offset over-harvesting and results in full efficiency. Allowing local communication within output-sharing groups substantially decreases this efficiency enhancement because it reduces free riding and boosts betweengroup competition. Yet the efficiency level is still significantly higher than that achieved when global communication is allowed among all appropriators in a conventional common pool resource without output sharing. The efficiency-reducing effect of local communication is mitigated when random partners instead of fixed partners are sharing output over time, and is nearly eliminated when random partners are formed with users who belong to different communication groups.
\end{abstract}

Keywords: Common pool resources, output sharing, partnership solution, communication, competition, group behavior, partners and strangers, experiments

JEL classification codes: Q20, C92, C72

\footnotetext{
${ }^{1}$ Corresponding Author, Email: jingjing.zhang@uts.edu.au. We received helpful comments from conference discussants and participants. Social Science and Humanities Research Council of Canada funded this research. Jingjing Zhang gratefully acknowledges financial support from the Swiss National Science Foundation (SNSF 135135) and the European Research Council (ERC Advanced Investigator Grant, ESEI-249433). Any views expressed in this paper are those of the authors alone.
} 


\section{The Effects of Communication on the Partnership Solution to the Commons}

"There is more than a verbal tie between the words common, community, and communication".

-John Dewey

\section{INTRODUCTION}

Since the late 1950s, economists have been searching for solutions to social dilemmas. One solution that has harnessed much support is allowing communication even when it is merely nonbinding "cheap talk" (Sally 1995; Bicchieri 2002; Balliet 2010). ${ }^{1}$ Experimental studies have shown that communication in common pool resources (CPRs) and voluntary contribution public good games improves cooperation and can overcome tragedy-of-the-commons and free-riding behavior (Isaac and Walker 1988; Hackett et al. 1994; Ostrom et al. 1994; Ledyard 1995; Chan et al. 1999; Kinukawa et al. 2000; Ahn et al. 2010). These studies suggest that the decentralized governance of CPRs and public goods is possible as long as agents are able to communicate with each other on a repeated basis. This conclusion on the positive effect of communication is drawn when considering only conflicts between individual and collective interest. There is a lack of studies that systematically examine whether and to what extent we can generalize this result to situations where multi-level conflicts exist on the individual, group and collective levels.

Researchers have long recognized that many social dilemmas involve multi-level interactions because groups instead of individuals are competing in providing public goods, extracting from CPRs or competing for market shares. The interplay of within-group conflict and between-group competition may sometimes mitigate the efficiency loss caused by each. Investigation of these complicated multi-level collective action problems has led to the invention of some clever methods to combine these competing forces and achieve better outcomes. Prominent examples include using inter-group competition to reduce free riding in within-group conflicts (Gunnthorsdottir and Rapoport 2005) and creating within-group free riding through the use of output-sharing groups to reduce excessive exploitation from a common pool (Schott 2001 and Heintzelman et al. 2009). In the latter case, the presence of groups that must share output extracted from the CPR creates a situation in which over-appropriators will reduce their extraction effort because they will have an incentive to free-ride on the effort of their group members. But these studies do not consider the role of communication in these mechanisms.

There are also several field examples of output-sharing partnerships involving common pools. Most traditional hunter-gatherer societies share their hunt with other households that do not necessarily participate in hunting or contribute to the financing of the harvest. These practices are still quite

\footnotetext{
${ }^{1}$ Note that throughout this paper we use the term "communication" to mean "non-binding and costless communication".
} 
dominant over large areas of the Arctic (Collings et al. 1998), in various Canadian provinces and in Australia whenever aboriginal groups are involved in the use and management of wildlife resources. In Japan a number of inshore and midshore fishing enterprises manage their resource by pooling their catch and distributing revenues equally among their group members (see Yamamoto 1995; Platteau and Seki 2001; Carpenter and Seki 2011). Japanese fishermen who pool their catch consistently have a higher catch per unit of effort than those in the same fishery and fishing area who do not. The Japanese fishermen's output-sharing schemes are similar to a fixed-group sharing scheme practiced by 'Uihan fishermen in Tonga in the South Pacific (Bender et al. 2002). This is in contrast with Lofangan fishermen, also from Tonga, who use a random-group informal sharing system (Chakraborty 2004) and have a significantly larger catch per unit of effort (Bender et al. 2002). These empirical observations illustrate the importance of carefully examining the influence of the type of partnership organization on the effectiveness of common pool resource management.

In most field contexts communication amongst individuals and groups of individuals is likely to be both possible and popular. Group members could be discussing common strategies; members of different groups may speak with one another either to coordinate actions or to provide deceptive information in attempts to gain strategic advantages, and members of groups may speak with others in social contexts when group memberships may be unknown. New means of electronic communication are evolving to allow people to communicate with others whom they never see or meet but with whom they work or against whom they compete. In such naturally occurring environments, with multi-level interactions, many channels of communication may arise. Different channels of communication may have opposing effects on the offsetting externalities. A better understanding of the impact of communication is highly relevant to how mechanisms such as output-sharing groups in a CPR function and perform.

We aim to bridge the literature on communication in the commons and the literature on outputsharing and the partnership solution by carefully studying a strategic situation in the laboratory where communication can be a double-edged sword depending on the specific communication channels available on different levels of interactions. The partnership solution to the CPR problem proposed by Schott (2001) provides an ideal environment for our purpose. With this management instrument, agents exploiting a CPR are placed in a number of output-sharing groups or partnerships. Members of each group must combine their harvest and share it equally. Equal sharing introduces a positive externality and provides an incentive for agents to reduce their harvesting effort and free ride on their partners. This shirking can offset the over-harvesting incentive characteristic of multiple agents appropriating from a common pool. Schott et al. (2007) demonstrated this effect in laboratory experiments and showed that groups allocate effort efficiently when the socially optimal output-sharing group size is established. 
Cherry et al. (2015) extend the work of Schott et al. (2007) by investigating the endogenous choice of the number of output-sharing groups that will form in a CPR via a voting mechanism. Neither Schott et al. (2007) nor Cherry et al. (2015) address the efficacy of output sharing as a management mechanism in environments with communication among the appropriators from the CPR.

The laboratory is an ideal setting to investigate communication and conflict since it allows us to add or remove communication channels in a controlled way so that we can tease out the main and interaction effects between communication and multi-level strategic interactions, which is not often feasible or observable in field studies. In our experiment, communication is introduced through computer-mediated chat rooms that allow messages to be exchanged among all agents (global communication) or within specific subgroups of agents (local communication) or both within subgroups and among all agents (local and global communication). Because we are considering the introduction of output-sharing groups into a CPR as an exogenous regulatory mechanism, we must distinguish between two kinds of groups. A communication group is a subgroup of agents whose members can communicate with each other concerning their decisions about the effort they will commit to appropriate from the CPR. These are distinct from output-sharing groups, which are created subgroups of agents who equally share the total appropriation of the group. Membership in the two groups may or may not consist of the same people. If the memberships differ, communication among members of a communication group may not have the same effect on effort exerted by members of the output-sharing groups as it would if the membership in the two groups is the same. This happens because it is not possible to agree to cooperate with a member of your output-sharing group if you do not know who is in your output-sharing group. In considering local communication we distinguish two cases: linked groups in which the memberships of the output-sharing groups and the communication groups are the same and unlinked groups in which they are different. The unlinked group reflects a world in which members of a distinct community regularly communicate among themselves, but are required to share output with others not necessarily from their community. We also allow output-sharing group composition to remain fixed across periods or to vary randomly. Random allocation to output-sharing groups allows us to investigate intra-group communication between strangers, and to examine whether the strong cooperation within groups to overcome free riding in other communication contexts persists if CPR groups are reassembled each period. $^{2}$

\footnotetext{
${ }^{2}$ Most studies have examined the effect of communication in inter-group games with fixed groups and a fixed prize (Rapoport and Bornstein 1989; Schram and Sonnemans 1996; Cason et al. 2012; Leibbrandt and Saaksvuori 2012 and Zhang 2012). Sutter and Strassmair (2009) examine the impact of communication in a group tournament in which the prize is not fixed and is paid by the losing team and shared equally in the winning team. They find that free riding dominates when teams cannot communicate or can only communicate with members of other teams. Communication within teams, on the other hand, increases individual contributions and efficiency. Contrary to
} 
We find that in our environment, organizing subjects into groups of four players who share output introduces sufficient free-riding incentives to achieve full efficiency. Local communication within output-sharing groups decreases efficiency by countervailing the free-riding incentives induced by output sharing and enhancing between-group competition. The reduced efficiency level with local communication and output sharing is, however, still significantly higher than simply allowing global communication among all resource users without output sharing. The efficiency-reducing effect of local communication is mitigated when random partners instead of fixed partners are sharing output over time, and is nearly eliminated when random partners are formed with users who belong to different communication groups.

\section{EXPERIMENTAL DESIGN AND PREDICTIONS}

In each decision period every participant is required to allocate a fixed endowment of effort, $e=28$, between a private activity, which provides a known return per unit of effort, $r=3.25$, and a resource extraction activity that provides a return that depends upon the aggregate effort of all 12 participants. The form of the yield function, parameters for the yield function, the opportunity cost of allocating the effort endowment, the effort endowment of participants in the CPR and the number of participants are identical to the values used in Schott et al. (2007). In the interest of brevity the term effort will henceforth refer only to the effort devoted to resource extraction, unless another interpretation is clearly required by the context. The experiment itself is conducted with neutral framing where effort is referred to as Investment and the two activities are identified as Market One and Market Two.

The total output from resource extraction is

$$
Y=32.5 X-0.09375 X^{2}
$$

where $Y$ is total output appropriated from the CPR and $X$ is the sum of the resource-extraction effort of all participants. In the conventional CPR environment without output sharing, which we shall refer to as the CPR treatment, each appropriator from the CPR receives a share of total output that is proportional to his effort. ${ }^{3}$ Thus the individual profit function (in lab dollars) in the CPR treatment is

$$
\pi_{i}=r\left(e-x_{i}\right)+\frac{x_{i}}{X} Y
$$

where $x_{i}$ is the harvesting effort of individual $i$.

theirs, in our experiment incentives are not monotonic as higher group contributions may lead to lower efficiency due to the congestion externality and the non-linear payoff of the CPR.

${ }^{3}$ In this context a treatment is a combination of factors. Factors are variables that have two or more levels. For example, in this experiment output sharing is a factor that can take on a Boolean value of true or false. Similarly, local communication also is a factor that can take on a Boolean value of true or false. For the CPR treatment both output sharing and local communication factors are false. All of the factors used in this study along with their combinations (i.e. treatments) will be described below (see Treatment 2015). 
Output sharing is introduced by dividing the 12 participants into 3 groups of 4 . The assignment of participants to groups may be fixed for the duration of the session or randomly remixed after each period. Output is distributed to each group in proportion to the group's effort, $X_{g}$, and this output is distributed equally to all group members. The return to each unit of output is normalized to one lab dollar (L\$). Given the group size of 4 , the individual profit function (in lab dollars) under output sharing is

$$
\pi_{i}=r\left(e-x_{i}\right)+\frac{1}{4} \frac{X_{g}}{X} Y .
$$

Communication is introduced by allowing participants to exchange messages during a communication period that precedes each decision period. Messages are exchanged by way of a chat window that appears on the computer screens of the participants. ${ }^{4}$ After the communication period, individuals make private and anonymous decisions about the number of units of effort they will allocate to appropriate from the CPR. The remaining units of effort are automatically allocated to the private activity. In the outputsharing treatments participants share their output from the common pool amongst all output-sharing group members and are given a summary providing their earnings for the period, the average earnings of others in their group and the average earnings of others outside of their group.

Communication may be global or local. When it is global all messages appear on the screens of all 12 participants. When it is local, participants are grouped into three separate communication groups. Only members of a specific communication group see the messages sent by others in that group. When communication is both global and local, messages are sent from and received in separate windows. ${ }^{5}$ Individuals are not required to adhere to any agreement they may reach during the communication period.

Communication groups may be linked or unlinked to the output-sharing groups. When outputsharing and communication groups are linked, membership in the communication group is the same as membership in the output-sharing group. Group membership is either fixed or randomly assigned after each period. If groups are not linked the membership of the output-sharing groups are randomly remixed each period, while the membership of the communication group remains fixed. Having randomly remixed communication groups and fixed output-sharing groups is not a configuration that we expect to find in the field and so we do not consider this.

\footnotetext{
${ }^{4}$ Janssen et al. (2010) introduce chat-room communication into a CPR setting in which it is possible to destroy the CPR by over appropriation. Chat-room communication is successful in forestalling destruction of the CPR and raising profit. This result is similar to the results reported by Muller and Vickers (1996) who use face-to-face communication. Bochet et al. (2006) compare different forms of communication in public goods laboratory experiments and find little difference between the effects of face-to-face communication and verbal communication through a chat room.

${ }^{5}$ Prior to the first decision round, individuals are given four minutes to send messages. Prior to the second and third decision rounds, individuals are given three minutes to communicate. Prior to the fourth round this is set at two minutes and from the fifth through the fifteenth rounds, communication is limited to one minute. These time limits were based on debriefing subjects after several pilot sessions.
} 
To systematically examine the impact of communication on the effectiveness of the partnership solution to the commons problem, we investigate the interplay of five factors that may influence the level of system effort and hence the efficiency of outcomes. These factors are Global Communication across all agents, Local Communication within groups, Fixed-Partners group assignment, Random-Partners group assignment after each period and Unlinked Communication and Output-Sharing Groups. Each factor has two values: 1 if present and 0 otherwise. Different combinations of these factor levels constitute the treatments we study. The treatment for which every factor takes a value of 0 is the conventional CPR environment (with no communication and no output sharing). Local Communication was only examined in the context of output sharing. The treatments with Fixed-Partners and RandomPartners output-sharing groups without communication that are introduced here are identical to those used in Schott et al. (2007) for the output-sharing environments with group size of 4 . We, therefore, study combinations of the five factors in twelve distinct treatments. The treatments and their names are presented in Table 1, and are organized by communication and output-sharing characteristics. Predictions for expected system effort for each of the twelve treatments are presented in subsections 2.1 through 2.5.

\section{[Insert Table 1 about here]}

\subsection{Equilibrium Predictions: No Communication with and without Output-Sharing Groups}

The basic CPR environment has no output sharing and no communication and presents a standard CPR dilemma. In our environment, 12 subjects make independent appropriation-effort decisions in an attempt to maximize the profit function given by equation (2). The Nash equilibrium for this environment has each appropriator exerting 24 units of effort to extraction from the CPR (288 for aggregate system effort). This is Prediction la.

In the Fixed-Partners and Random-Partners treatments with three four-person output-sharing groups each appropriator will maximize the profit function given by equation (3). Output sharing induces appropriators to free-ride on the members of their output-sharing groups and this will constrain the overextraction present in this environment. The unique group-Nash-equilibrium effort for each of the three four-person groups is 52, regardless of whether group membership is fixed over the session or randomly reassigned after each decision round. This also is the surplus-maximizing allocation of effort. There is no unique equilibrium allocation of group effort for individuals in the group but the equilibrium system effort of 156 is unique. ${ }^{6}$ This is Prediction $1 b$.

\subsection{Equilibrium Predictions: Global Communication with and without Output-Sharing Groups}

\footnotetext{
${ }^{6}$ See section 1 of Appendix III for a derivation of the equilibrium results. See Schott et al. (2007) for the derivation of the optimal effort to allocate to appropriation from the common pool.
} 
Communication can inform players of the beliefs of other players. If actions reaffirm these beliefs, then cooperation may be sustainable in a repeated-game setting (see Hackett et al. 1994, pp. 107-108). There are few behavioral models of decision-making in a CPR environment with communication from which we can derive a prediction about the role of communication. However, for environments such as ours, the empirical evidence strongly suggests that treatments that include global communication without output sharing would reduce system effort and increase efficiency significantly relative to the basic CPR environment without global communication (see Ostrom et al., 1994, Chapters 7, 8; Muller and Vickers, 1996). Therefore, we expect that effort in the CPR with Global Communication will be less than 288 units. This is Prediction 2a. Because equilibrium output is predicted to be optimal in output-sharing environments without communication, the introduction of global communication is likely to have no effect and our expected system effort is 156 for the Fixed-Partners with Global Communication and Random-Partners with Global Communication treatments. This is Prediction $2 b$.

\subsection{Equilibrium Predictions: Local Communication and Output Sharing with Linked Fixed and Random}

\section{Partners}

When communication groups are linked with output-sharing groups it is possible for the participants within the output-sharing groups to discuss extraction strategies. Joint and individual payoffs within a group will be maximized if the linked communication and output-sharing group acts as a single economic agent in competition against other output-sharing groups. Thus, each group would maximize a profit function represented by equation (3) aggregated over its four group members.

If all groups behave this way there will be a system-wide group profit-maximizing equilibrium consistent with a three-agent Nash equilibrium. This will yield a unique group Nash equilibrium level of extraction effort of 78 units (234 units for the system). ${ }^{7}$ In this context, local communication among output-sharing group members will lead to the reduction of shirking and a system-wide increase in effort relative to the no-communication equilibrium for the Fixed-Partners or Random-Partners treatments. System effort for the Linked Fixed-Partners with Local Communication treatment will be 234 units. This is Prediction $3 a$.

However, the outcome will still be more efficient than that expected to be obtained in the basic CPR treatment. Because communication requires repeated interactions and reinforcement it is less likely that the group profit-maximizing equilibrium will be realized when linked output-sharing groups are randomly reassigned each decision round than when they are fixed for the session. We therefore expect system effort to be between 156 and 234 for the Linked Random-Partners with Local Communication

\footnotetext{
${ }^{7}$ There is no unique individual extraction effort. See section 2 of Appendix III for this derivation.
} 
treatment. Randomizing partners over time might mitigate the effort-enhancing effect of local communication when communication and output-sharing groups are linked. This is Prediction $3 b$.

Generally, for linked local-communication and output-sharing groups, effort is expected to rise from levels without local communication. This is Prediction $3 c$.

\subsection{Equilibrium Predictions: Global and Local Communication and Output Sharing with Linked Fixed} and Random Partners

For the Linked Random-Partners and Fixed-Partners with Local Communication treatments, allowing global communication may result in reduced effort. The possible equilibrium range of outcomes of system effort for the Linked Random-Partners and Fixed-Partners with Global and Local Communication treatments is, at the high end, 234 units (78 units by each group; no change from the outcome for the Linked Fixed-Partners with Local Communication treatment). At the low end, however, it is 156 units (52 units by each group; a coordinated efficient outcome enabled by the introduction of global communication resulting from the three groups entering into a three-player coalition-proof Nash equilibrium). This optimal allocation of effort is described by Moldovanu (1992) and is derived for this particular parameter set in Appendix III.3. Therefore, the introduction of global communication should result in system effort lower than in the absence of global communication for both the Fixed-Partners with Local Communication treatment (Prediction 4a) and for the Random-Partners with Local Communication treatment (Prediction 4b)

Because of the coordination and adjustment issues described earlier for the Random-Partners treatments, it is more likely that the impact of global communication on system effort will be greater for the Fixed-Partners treatments. This is Prediction $4 c$.

\subsection{Equilibrium Predictions: Global and Local Communication and Output Sharing with Unlinked} Random Partners

When local-communication groups are not linked with output-sharing groups it is not possible for the participants within the output-sharing groups to discuss extraction strategies among themselves. If the appropriators of the CPR are able to communicate in fixed groups that are different from their outputsharing groups, and if the output-sharing groups are randomly reassigned each period then we expect that system effort would be the same as for the Random-Partners treatment without communication. Therefore system effort for treatment with unlinked random partners and local communication is expected to be 156 units.

Just as the introduction of local communication could lead to a reduction in shirking among members of an output-sharing group, the introduction of global communication could lead to a coordinated reduction of effort by all members of the CPR. The introduction of global communication is 
not likely to alter the outcomes of those treatments that are already expected to realize an efficient system effort of 156 units. Therefore the expected system effort for the Unlinked Random-Partners with Local Communication treatment and the Unlinked Random-Partners with Global and Local Communication treatment is 156. These are Predictions $5 a$ and $5 b$. Associated with these predictions is the prediction that system effort will be lower in Unlinked Random-Partners treatments than in Linked Random-Partners treatments. This is Prediction 5c.

All of the predicted system effort outcomes introduced above are presented in Table 2 along with the mean system effort resulting from the laboratory implementation of each of the twelve different treatments.

[Insert Table 2 about here]

\subsection{Experimental Procedures}

A total of 576 subjects from McMaster University participated in the experiment. The experiment consisted of 4 sessions for each of 12 treatments. Of the 48 sessions whose results are reported in this paper, 9 were run earlier and reported in Schott et al. (2007): 3 sessions with the basic CPR treatment, 3 Fixed-Partners treatments and 3 Random-Partners treatments. Of the remaining 39 sessions, 36 sessions were run to introduce communication into the CPR environments. The other 3 sessions were one each of the basic CPR treatment, the Fixed-Partners treatment and the Random-Partners treatment. ${ }^{8}$ In each session, 12 subjects participated in 15 decision rounds after three practice rounds. Laboratory currency was converted at the exchange rate of L\$200 for 1 Canadian dollar. On average, subjects earned $\$ 23.82$ each (the standard deviation was $\$ 3.12$ and earnings ranged from $\$ 15.42$ to $\$ 30.30$ including a $\$ 5$ showup fee). Sessions were completed within 60 minutes in treatments without communication and within 90 minutes in treatments with communication.

\section{RESULTS}

Figure 1 presents the mean system effort by treatment. The equilibrium predictions for each treatment and the realized mean system efforts for each treatment are provided in Table 2. There are 48 independent session observations. We regress mean system effort, computed over the entire session, on the five factors and their interactions. We use robust (heteroscedasticity consistent) standard errors. The

\footnotetext{
${ }^{8}$ Adding an additional observation to the data for the basic CPR treatment, the Fixed-Partners treatment and the Random-Partners treatment reported in Schott et al. (2007) does not affect the results obtained by Schott et al. (2007) that the system effort for each treatment is not different from the predicted values. In all cases the p-values for the statistical tests are greater than 0.10 regardless of whether the additional observation is added.
} 
constant in the regression is the mean system effort associated with the CPR treatment. The regression results are presented in Table 3. Statistical tests in the remainder of the paper use the robust standard errors from this regression unless otherwise noted. Results from appropriate non-parametric versions of these tests are also presented. We analyse the results under the five headings corresponding to the headings containing predictions in Section 2.

\section{[Insert Figure 1 about here]}

\subsection{No Communication with and without Output Sharing}

In this sub-section we test hypotheses related to the basic CPR, the Fixed-Partners and the RandomPartners treatments. The hypotheses concern the performance of the participants in these treatments relative to the theoretical predictions for these treatments. The parametric tests are based on the results reported in Table 3. For example, the system mean effort in the Fixed-Partners treatment is equal to the sum of the coefficients for the constant (284.22; this represents the absence of output sharing and any communication, which is the CPR treatment) and the fixed-partners factor (-133.82). This is equal to 150.40. Using the statistical software package STATA ${ }^{\circledR}$ we can test the difference between the sum of these two coefficients and 156, which is the predicted value for this treatment.

[Insert Table 3 about here]

The mean system effort in the basic CPR treatment is 284.22. This is not significantly different from the Nash equilibrium of 288 (F-test, $p=0.133$; Wilcoxon Signed-Ranks test, $N=4, p>0.10$ ). ${ }^{9}$ For the Fixed-Partners treatment mean system effort is 150.40 (3.5\% below the predicted optimal effort and nearly $50 \%$ below the Nash equilibrium effort). This is 134 units below system effort for the CPR treatment and below the system optimum of 156 but not significantly different from the latter (F-test, $\mathrm{p}=$ 0.138; Wilcoxon Signed-Ranks test, $N=4, p>0.10$ ). The Random-Partners treatment results in mean effort of 152.77, 131 units below the system effort for the CPR treatment. Again, this is not significantly different from the predicted optimal effort (F-test, $p=0.752$; Wilcoxon Signed-Ranks test, $N=4, p>$ 0.10). The means for the Fixed-Partners and Random-Partners treatments are not significantly different from each other (F-test, $\mathrm{p}=0.828$; Mann-Whitney U-test, $\mathrm{N}_{1}=4, \mathrm{~N}_{2}=4, \mathrm{p}=0.557$ ) and both are significantly lower than the mean for the CPR treatment (F-tests, $\mathrm{p}=0.000$; Mann-Whitney U-tests, $\mathrm{N}_{1}=$ $4, \mathrm{~N}_{2}=4, \mathrm{p}=0.029$ ). These relationships are displayed in Table 2 and by the three bars in the right-most column of Figure 1. The data support Predictions $1 a$ and $1 b$ and establish Result 1.

\footnotetext{
${ }^{9}$ All reported p-values are based on two-sided tests unless otherwise stated. One-sided tests are used only when the prediction implies a direction for the change.
} 
Result 1. The CPR treatment (with no communication or output sharing) leads to the overappropriation predicted as the Nash equilibrium for this environment. The FixedPartners and Random-Partners treatments (which implement an output-sharing mechanism) lead to full efficiency. The assignment of partners to groups (fixed versus random) does not affect the effectiveness of the output-sharing mechanism in the absence of communication.

\subsection{Global Communication with and without Output-Sharing Groups}

This sub-section concerns the performance of the participants in the basic CPR with Global Communication, the Fixed-Partners with Global Communication and the Random-Partners with Global Communication treatments relative to the theoretical predictions for these environments. The parametric tests are based on the results reported in Table 3; for example, the effect of introducing global communication on system effort in the Fixed-Partners treatment is the sum of the coefficients of G (the global communication factor) and G \& F (the interaction between the global communication and fixedpartners treatments) in Table 3 . The significance of this sum, approximately 15 , can be tested directly using these coefficients and their standard errors).

Adding global communication to the basic CPR treatment reduces mean system effort by 22 units (about $8 \%$ ) to 262.70 . This effect is statistically significant in the direction predicted (t-test, $\mathrm{p}=0.023$; Mann-Whitney U-test, $\mathrm{N}_{1}=4, \mathrm{~N}_{2}=4, \mathrm{p}=0.057$; both 1-sided) but a much larger reduction in effort (128 units) is required to reach the system optimum of 156. Adding global communication to the FixedPartners treatment actually raises mean effort by 15 units to 165 (about 10\%). The effect is not statistically significant (F-test, $\mathrm{p}=0.151$; Mann-Whitney U-test, $\mathrm{N}_{1}=4, \mathrm{~N}_{2}=4, \mathrm{p}=0.20$ ). When global communication is added to the Random-Partners treatment, mean effort rises by 16 units to 169 (again, about $10 \%$ ). This effect is not significant (F-test, $\mathrm{p}=0.222$; Mann-Whitney U-test, $\mathrm{N}_{1}=4, \mathrm{~N}_{2}=4, \mathrm{p}=$ 0.343). These relationships are displayed in Table 2 and Figure 1 (the three bars in the second right column). The data support Predictions $2 a$ and $2 b$ and establish Results 2 and 3.

Result 2. Global communication reduces effort and increases efficiency when there is no output sharing but effort remains much above optimal levels.

Result 3. Global communication tends to increase effort and to reduce efficiency when introduced into the Fixed-Partners or Random-Partners treatments but the effect is small and not statistically significant. Output sharing is somewhat less effective in the presence of Global communication, but continues to achieve near-optimal results.

\subsection{Local Communication and Output Sharing with Linked Fixed and Random Partners}


We now turn to the effects of local communication and group assignment in the presence of output sharing. We focus on the Linked Fixed-Partners and Random-Partners with and without Local Communication treatments presented in the two middle rows of Table 1. The predicted values of system effort and the realized system effort for these treatments are presented in Table 2.

From Table 2 we see that mean system effort for the Linked Fixed-Partners with Local Communication treatment is 227.92 units. The predicted group profit maximizing system effort is 234 units. The six-unit difference is not statistically significant (F-test, $\mathrm{p}=0.090$, Wilcoxon Signed-Ranks test, $\mathrm{N}=4, \mathrm{p}>0.10$ ). Also from Table 2 we see that the mean system effort for the Linked RandomPartners with Local Communication treatment is 186.57 units. This falls within the predicted range of 156 to 234 units. Both of these treatments generated mean system efforts that are significantly greater than the levels for the corresponding Fixed-Partners and Random-Partners treatments (without communication). The difference is 77.52 units for the Linked Fixed-Partners treatment (F-test, $\mathrm{p}=0.000$, Mann-Whitney U-test, $\left.\mathrm{N}_{1}=4, \mathrm{~N}_{2}=4, \mathrm{p}=0.029\right)$ and 33.80 for the Linked Random-Partners treatment (F-test, $\mathrm{p}=0.006$, Mann-Whitney U-test, $\mathrm{N}_{1}=4, \mathrm{~N}_{2}=4, \mathrm{p}=0.057$ ). The increase in effort is greater for the Linked Fixed-Partners with Local Communication treatment than for the comparable RandomPartners treatment. These results support Predictions $3 a$ and $3 b$ and $3 c$ and establish Results 4 and 5.

Result 4. Local communication has a strong effort-enhancing effect when introduced into FixedPartners and Random-Partners treatments with linked communication and outputsharing groups.

Result 5. Randomized group assignment mitigates but does not eliminate the effort-enhancing and efficiency-reducing effect of local communication.

\subsection{Global and Local Communication and Output Sharing with Linked Fixed and Random Partners}

The introduction of global communication into Linked Fixed-Partners and Random-Partners with Local Communication treatments results in mean system effort falling from 227.92 units to 210.82 and 186.57 to 180.90 respectively. These differences are significant for the Fixed-Partners treatment but not for the Random-Partners treatment (F-tests, $\mathrm{p}=0.036$ and $\mathrm{p}=0.652$; Mann-Whitney U-test, $\mathrm{N}_{1}=4, \mathrm{~N}_{2}=4, \mathrm{p}=$ 0.057 and $p=0.686$ ). The reductions in mean system effort for the Linked Fixed-Partners and Linked Random-Partners with Local and Global Communication treatments are 17.10 and 5.67 units respectively. Although these differences are of the predicted magnitudes, they are not significantly different (F-test, $\mathrm{p}=$ 0.443). The data support Prediction $4 a$ but not Predictions $4 b$ and $4 c$. Result 6 follows.

Result 6. Global communication mitigates the effect of local communication, reducing effort and increasing efficiency in the Linked Fixed-Partners but not in the Random-Partners with 


\section{Local Communication Treatment.}

\subsection{Global and Local Communication and Output Sharing with Unlinked Random Partners}

Table 2 presents the mean system efforts associated with Unlinked Random-Partners treatments with Local Communication and with Local and Global Communication. For the treatment without Global Communication, mean system effort is 166.87 units, which is not statistically different from the predicted effort of 156 units (F-test, $\mathrm{p}=0.215$; Wilcoxon Signed-Ranks test, $\mathrm{N}=4, \mathrm{p}>0.10$ ). With Global

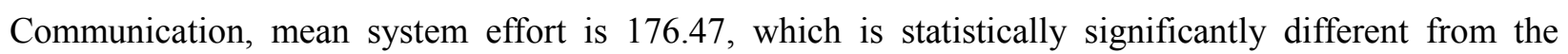
predicted effort level of 156 (F-test, $\mathrm{p}=0.000$; Wilcoxon Signed-Ranks test, $\mathrm{N}=4, \mathrm{p}=0.10) .{ }^{10}$ For both of these Unlinked treatments, mean system effort is less than for the comparable Linked Random-Partners (19.70 units and 4.43 units for treatments with and without global communication, 1-sided t-tests, $\mathrm{p}=$ 0.051 for the former and $\mathrm{p}=0.358$ for the latter and Mann-Whitney U-test, $\mathrm{N}_{1}=4, \mathrm{~N}_{2}=4, \mathrm{p}=0.10$ for the former and $\mathrm{p}=0.557$ for the latter). As well, the system efforts for the unlinked treatments are less that for the comparable Linked Fixed-Partners treatments (61.05 units and 33.35 units for treatments with and without global communication; 1-sided t-tests, $\mathrm{p}=0.001$ and $\mathrm{p}=0.004$ and Mann-Whitney U-test, $\mathrm{N}_{1}$ $=4, \mathrm{~N}_{2}=4, \mathrm{p}=0.143$ for both pairs). The data support Predictions $5 a, 5 b$ and $5 c$ and establish Result 7 .

Result 7. Breaking the link between output-sharing and local communication groups nearly eliminates the effort-enhancing effect of local communication and leads to nearly optimal system effort that is much lower than in Linked Fixed-Partners and Linked RandomPartners with Local Communication treatments (with or without Global Communication).

\subsection{Unpredicted Results}

There are several outcomes that were not predicted that are worth presenting at this time. The literature addressing the role of communication in managing the over-appropriation from the commons provides many examples of communication facilitating optimal or near optimal appropriation in laboratory environments. While we predicted that global communication would lead to a reduction in appropriation, we made no prediction about the relative effectiveness of introducing global communication to the effectiveness of managing the commons with an output-sharing mechanism. Our results show that introducing global communication into the basic CPR treatment reduces effort by 21.52 units. The introduction of output sharing reduces effort by 133.82 units in the Fixed-Partners treatment and by 131.45 units in the Random-Partners treatment. These latter two reductions are significantly greater than the reduction associated with introducing global communication into the CPR treatment $(\mathrm{F}-\mathrm{tests}, \mathrm{p}=$

\footnotetext{
${ }^{10}$ A test comparing the data for the mean system efforts of the two treatments supports the null hypothesis that there is no difference between the two means (F-test, $\mathrm{p}=0.299$, Mann Whitney U-test, $\mathrm{p}=0.343$ )
} 
0.000; Mann-Whitney U-tests, $\mathrm{p}=0.057$ for the comparison with the Fixed-Partners treatment and $\mathrm{p}=$ 0.0143 for the comparison with the Random-Partners treatment).

Result 8. Output sharing in the absence of communication is more effective at managing overappropriation from the commons than global communication.

A second relationship about which we made no prediction was how the increases in system effort anticipated with the introduction of local communication into the Fixed-Partners and Random-Partners treatments would compare with the lower system effort anticipated from the CPR with Global Communication treatment. From Table 2 we see the CPR with Global Communication treatment results in mean system effort of 263 units. The Linked Fixed-Partners and Linked Random-Partners with Local Communication treatments resulted in mean system efforts of 228 and 187 units respectively. For both output-sharing treatments with local communication mean system effort is significantly lower than in the treatment with global communication but without output sharing (F-test, $\mathrm{p}=0.003$; Mann-Whitney Utest, $\mathrm{N}_{1}=4, \mathrm{~N}_{2}=4, \mathrm{p}=0.057$ for the treatment with fixed partners and F-test, $\mathrm{p}=0.000$; Mann-Whitney U-test, $\mathrm{N}_{1}=4, \mathrm{~N}_{2}=4, \mathrm{p}=0.029$ for the treatment with random partners).

Result 9. The efficiency-diminishing effects of local communication in output-sharing treatments still results in the output-sharing treatments outperforming the CPR with Global Communication treatment.

\section{DISCUSSION AND CONCLUSION}

In the absence of output sharing and communication we have a conventional CPR treatment with a larger number of participants than typically used in a laboratory experimental study. In this treatment participants jointly apply the amount of system effort predicted as the Nash equilibrium. It is significantly greater than the optimal system effort. Introducing global communication across all subjects reduces system effort and enhances efficiency, although to a significantly lesser degree than found in the literature (see, for example, the small endowment environment in Ostrom et al. 1994). Introducing an externality to offset the one inherent to the CPR through the use of output sharing proved to be far more effective in managing the laboratory CPR than introducing global communication and indeed achieves efficient levels of effort.

However, the performance of the Fixed-Partners and Random-Partners treatments was substantially weakened when output sharing was augmented with local communication. Local communication within output-sharing groups results in substantially increased extraction effort because it allows coordinated decision-making within output-sharing groups, reduces shirking and supports inter- 
group competition. Although the presence of local communication within the Linked Fixed-Partners and Random-Partners treatments causes effort to rise above efficient levels these treatments are still significantly more efficient than our laboratory CPR with Global Communication treatment. Global communication does, however, increase efficiency by reducing system effort from that realized in the Linked Fixed-Partners with Local Communication treatments.

Therefore our laboratory evidence supports the use of mechanisms that introduce countervailing externalities in the management of environments involving social dilemmas. In particular, we have found that managing a CPR with output-sharing groups can substantially improve extraction outcomes towards the social optimum, dominating solutions such as global communication, even when members of these output-sharing groups can communicate locally with one another.

Our findings also have important implications for practical attempts to achieve decentralized management through output sharing in groups. Local communication within output-sharing groups is a real threat to such management. The findings from our unlinked and linked output-sharing groups with random assignment suggest that to effectively manage the commons, it is important to offset the coordinating effects of local communication by maintaining the anonymity of output-sharing group members and regularly reconstituting their membership. Separating output-sharing groups from communication groups is particularly useful and randomizing output-sharing groups in a way that breaks the link between output sharing and communication is valuable. This is an exercise that a regulatory body run by a central authority could do, although it may not always be feasible. If recurrent local communication among output-sharing group members cannot be eliminated, an alternative action may be to reduce the number of output-sharing groups below the optimal number associated with a world of no communication. The smaller number of output-sharing groups in the absence of global communication will lead to lower system effort than with the larger number of output-sharing groups (using the parameters in this experiment and the first-order conditions in Appendix III.2, three groups of four exert 234 effort units of appropriation but two groups of six would exert 208 effort units). The introduction of global communication may result in a further reduction of effort. In either case, if only one can be used, output sharing trumps global communication as a management tool in the commons environment we have studied in the laboratory.

In this study we have carefully analyzed the impacts of local communication on the partnership solution to the common's problem and the ability of global communication alone to solve the social dilemma. In practice, different forms of communication will always be prevalent. Our results suggest that management solutions need to properly account for various communication channels and group settings, particularly as the number of actors becomes larger and we cannot rely on even repeated "cheap 
talk" to achieve efficient results. Partnerships are one way of organizing and sharing a common pool resource such as certain fisheries, land and marine mammals, grazing lands or aquifers. Hunter-gatherer cultures that have survived to modern times may owe their success to their practice of sharing their harvest caught by teams of hunters and fishers because extensive sharing reduces hunting effort sufficiently to protect common property from over-exploitation (Cherry et al. 2015; Kagi 2001; Sahlins 1972). Examples can be found in virtually all traditional societies, e.g. in Canada's North for the harvest of fish, marine and land mammals (Collings et al. 1998; Harder and Wenzel 2012), fisheries in the South Pacific (Bender et al. 2002) and inshore fisheries in Japan that pool catch among vessels and share it equally (Yamamoto 1995; Platteau and Saki 2000). The impact of the change in communication groups (through social media, web information and E-mail) and the change in sharing networks and type of partnerships on the use and conservation of common pool resources will need to be better understood and evaluated for more effective wildlife and fishery management solutions.

Our insights on communication channels and the partnership solution can also be applied to evaluate and improve other management tools that introduce counteracting externalities in environments involving social dilemmas and unobservable effort. For example, to avoid wasteful duplication in innovation tournaments, researchers often form joint ventures that compete to develop the best innovation and share the benefits within their own group (Baye and Hoppe 2003). In professional sports leagues, revenue sharing is used to reduce overinvestment in attracting fans, talented players, coaches and to maintain the right competitive balance to maximize aggregate league revenue (Atkinson et al. 1988; Dietl et al. 2008). Moreover, team regrouping is actually a common practice in the business world. Quite often teams are formed when a specific problem arises, and dissolved right after the problem is solved. Such short-lived problem-solving teams are not only popular among law firms, consulting firms and medical group partnerships, but also are increasingly popular among manufacturing or service firms (Boning et al. 2007). This suggests that our proposal of randomizing output-sharing groups or to separate communication groups from output-sharing groups to offset the negative effect of local communication is not only of a theoretical interest, but also has a basis in practice as well. 


\section{REFERENCES}

Ahn TK, Ostrom E, Walker J (2010) A common-pool resource experiment with postgraduate subjects from 41 countries. Ecol Econ 69: 2624-2633.

Atkinson S, Stanley L, Tschirhart, J (1988) Revenue sharing as an incentive in an agency problem: an example from the national football league, RAND J Econ 19: 27-43.

Balliet D (2010) Communication and cooperation in social dilemmas: a meta-analytic review. J Conflict Res 54(1): 39-57.

Baye, M.R., and Hoppe, H.C. (2003). The Strategic Equivalence of Rent-seeking, Innovation, and Patentrace Games, Games and Economic Behavior, 44(2), 217-226.

Bender, A., Kägi, W., \& Mohr, E.. (2002). Informal Insurance and Sustainable Management of Common Pool Marine Resources in Ha'apai, Tonga. Economic Development and Cultural Change, 50(2), 427-439.

Bicchieri, C. (2002). Covenants Without Swords: Group Identity, Norms, and Communication in Social Dilemmas. Rationality and Society, 14(2), 192-228.

Bochet, O., Page, T. and Putterman, L. (2006). Communication and Punishment in Voluntary Contribution Experiments. Journal of Economic Behavior and Organization, 60 (1), 11-26.

Boning, B., Ichniowski, C. and Shaw, K. (2007) Opportunity Counts: Teams and the Effectiveness of Production Incentives, Journal of Labor Economics, 25, 613-650.

Carpenter, J. and Seki, E. (2011). Do Social Preferences Increase Productivity? Field Experimental Evidence from Fishermen in Toyoma Bay. Economic Inquiry, 49(2), 612-630.

Cason, T. N., Sheremeta, R. M. and Zhang, J. (2012). Communication and Efficiency in Competitive Coordination Games. Games and Economic Behavior, 76, 2012, 26-43.

Chakraborty, R. N. (2004). Sharing rules and the commons: evidence from Ha'apai, Tonga. Environment and Development Economics 9: 455-472.

Chan, K. S., Mestelman, S., Moir, R. and Muller, R. A. (1999). Heterogeneity and the Voluntary Provision of Public Goods. Experimental Economics, 2, 5-30.

Cherry, J., Salant, S. and Uler, N. (2015). Experimental Departures from Self-Interest when Competing Partnerships Share Output. Experimental Economics, 18, 89-115.

Chung, T.-Y. (1996). Rent-Seeking Contest When the Prize Increases with Aggregate Efforts. Public Choice, 87, 1-2, 55-66.

Collings, P., Wenzel, G. and Condon, R.G. (1998). Modern Food Sharing Networks and Community Integration in the Central Canadian Arctic. Arctic, Vol. 51, No. 4, 301-314.

Dietl, H., Franck, E. and Lang, M.(2008). Overinvestment in Team Sports: A Contest Theory Model., Scottish Journal of Political Economy, 55, 353-368.

Gunnthorsdottir, A. and Rapoport, A. (2006). Embedding Social Dilemmas in Intergroup Competition Reduces Free-riding. Organizational Behavior and Human Decision Processes, 101, 184-199.

Hackett, S., Schlager, E. and Walker, J. M. (1994). The Role of Communication in Resolving Commons Dilemmas: Experimental Evidence with Heterogeneous Appropriators. Journal of Environmental Economics and Management, 27 (2), 99-126.

Harder, M.T. and Wenzel, G.W. (2012), Inuit Subsistence, Social Economy and Food Security in Clyde River, Nunavut, Arctic, Vol. 65, No. 3, p. $305-318$.

Heintzelman, M.D., Salant, S.W. and Schott, S. (2009). Putting Free-riding to Work: A Partnership Solution to the Common-property Problem. Journal of Environmental Economics and Management, 57 (3), 309-320.

Isaac, R. M. and Walker, J. M. (1988). Communication and Free-Riding Behavior: The Voluntary Contribution Mechanism. Economic Inquiry, 26, 586-608.

Janssen, M., Holahan, R., Lee, A., and Ostrom, E. (2010). Lab Experiments for the Study of SocialEcological Systems. Science, 328(5978), 613-617.

Kagi, W. (2001). The tragedy of the commons revisited: Sharing as a means to avoid environmental ruin. 
IWOE Discussion Paper 91, Institute for Economy and the Environment, University of St. Gallen.

Kinukawa, S, Saijo, T., and Une, M. (2000). Partial Communication in a Voluntary-ContributionMechanism Experiment. Pacific Economic Review, 5(3), 411-428.

Ledyard, J. O. (1995). Public Goods; A Survey of Experimental Research. In Kagel, J. and Roth, A. (editors), Handbook of Experimental Economics. Princeton University Press. Princeton, NJ.

Leibbrandt, A., Sääksvuori, L.(2012). Communication in Intergroup Conflicts, European Economic Review, 56, 1136-1147.

Moldovanu, B. (1992). Coalition-Proof Nash Equilibria and the Core in Three-Player Games, Games and Economic Behavior 4, 565-581 (1992).

Muller, R. A., and Vickers, M. (1996). Communication in a Common Pool Resource Environment with Probabilistic Destruction. McMaster University Department of Economics Working Paper 96-06.

Ostrom, E., Gardner, R and Walker, J. (1994). Rules, Games and Common-Pool Resources. Ann Arbor: The University of Michigan Press.

Platteau, J.-P. and Seki, E. (2001). Community Arrangements to Overcome Market Failure: Pooling Groups in Japanese Fisheries. In Aoki, M. and Hayami, Y. (editors), Communities and Markets in Economic Development. Clarendon Press, Oxford, 344-403.

Rapoport, A. and Bornstein, G. (1989). Solving Public Goods Problems in Competition between Equal and Unequal Size Groups. Journal of Conflict Resolution, 33, 460-479.

Sahlins, M. (1972). Stone age economics. New York: Aldine de Gruyter.

Sally, D. (1995). Conversation and Cooperation in Social Dilemmas: A Meta-analysis of Experiments from 1958 to 1992. Rationality and Society, 7, 58-92.

Schott, S. (2001). A Partnership Solution to the Tragedy of the Commons. 4th Toulouse Conference on Environment and Resource Economics, Toulouse, France, May 2001.

Schott, S., Buckley, N., Mestelman, S. and Muller, R. A. (2007). Output Sharing in Partnerships as a Common Pool Resource Management Instrument. Environmental and Resource Economics, 37 (4), 697-711.

Schram, A. and Sonnemans, J. (1996). Why People Vote: Experimental Evidence. Journal of Economic Psychology, 17, 417-442.

Sutter, M. and C. Strassmair (2009). Communication, Cooperation and Collusion in Team Tournaments: An Experimental Study. Games and Economic Behavior, 66(1), 506-525.

Treatment (2015) In Wikipedia, Retrieved October 18, 2016, from https://en.wikipedia.org/wiki/Glossary of experimental_design

Yamamoto T. (1995). Development of Community-based Fishery Management System in Japan. Marine Resource Economics, 10, 21-34.

Zhang, J. (2012). Communication in Asymmetric Group Competition over Public Goods. University of Zurich, Working paper series, No. 69. 


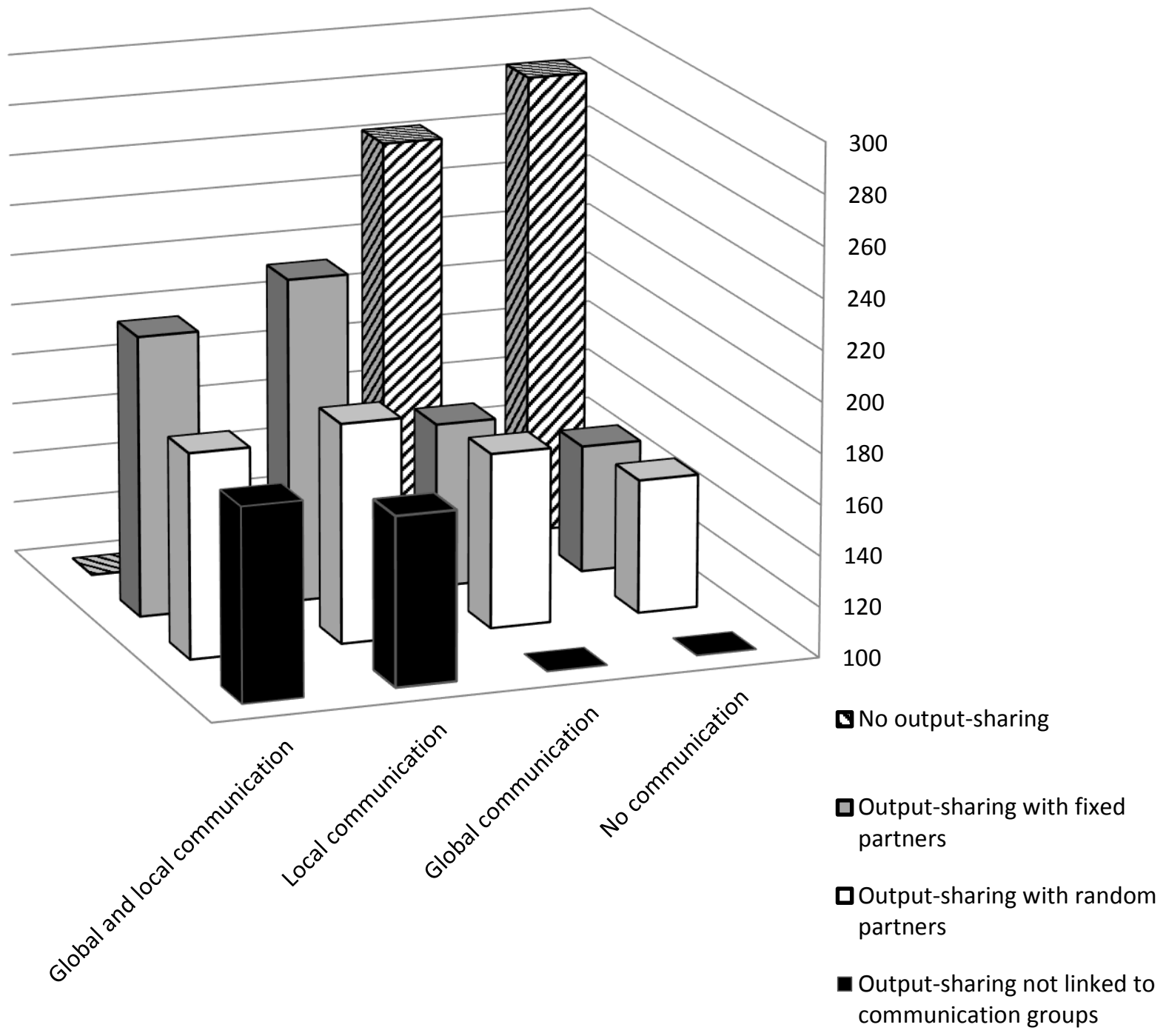

Figure 1. Mean System Effort by Treatments 
Table 1. Twelve treatments as a combination of output-sharing and communication factors

\begin{tabular}{|c|c|c|c|c|}
\hline & $\begin{array}{l}\text { No } \\
\text { Communication }\end{array}$ & $\begin{array}{l}\text { Global } \\
\text { Communication }\end{array}$ & $\begin{array}{l}\text { Local } \\
\text { Communication }\end{array}$ & $\begin{array}{l}\text { Global and Local } \\
\text { Communication }\end{array}$ \\
\hline $\begin{array}{l}\text { No Output } \\
\text { Sharing }\end{array}$ & $\mathrm{CPR}$ & $\begin{array}{l}\text { CPR with Global } \\
\text { Communication }\end{array}$ & Not Applicable & Not Applicable \\
\hline $\begin{array}{l}\text { Output Sharing } \\
\text { with Fixed } \\
\text { Partners }\end{array}$ & Fixed Partners & $\begin{array}{l}\text { Fixed Partners with } \\
\text { Global } \\
\text { Communication }\end{array}$ & $\begin{array}{l}\text { Linked Fixed } \\
\text { Partners with } \\
\text { Local } \\
\text { Communication }\end{array}$ & $\begin{array}{l}\text { Linked Fixed } \\
\text { Partners with } \\
\text { Global and Local } \\
\text { Communication }\end{array}$ \\
\hline $\begin{array}{l}\text { Output Sharing } \\
\text { with Random } \\
\text { Partners }\end{array}$ & Random Partners & $\begin{array}{l}\text { Random Partners } \\
\text { with Global } \\
\text { Communication }\end{array}$ & $\begin{array}{l}\text { Linked Random } \\
\text { Partners with } \\
\text { Local } \\
\text { Communication }\end{array}$ & $\begin{array}{l}\text { Linked Random } \\
\text { Partners with } \\
\text { Global and Local } \\
\text { Communication }\end{array}$ \\
\hline $\begin{array}{l}\text { Output Sharing } \\
\text { Not Linked to } \\
\text { Fixed Commun- } \\
\text { ication Groups }\end{array}$ & Not Applicable & Not Applicable & $\begin{array}{l}\text { Unlinked } \\
\text { Random Partners } \\
\text { with Local } \\
\text { Communication }\end{array}$ & $\begin{array}{l}\text { Unlinked } \\
\text { Random Partners } \\
\text { with Global and } \\
\text { Local } \\
\text { Communication }\end{array}$ \\
\hline
\end{tabular}

Note: The four shaded cells in Table 1 represent configurations of the communication and outputsharing conditions that cannot exist. The remaining twelve cells represent the twelve treatments studied in this experiment. We could have examined both output sharing groups with random partners and unlinked fixed communication groups and output sharing groups with fixed partners and unlinked random communication groups but chose to only examine the former because we believe the fixed communication groups are most common in the field (representative of costless communication within social or community groups). These are described in more detail in the subsections 2.1 through 2.5. Instructions for unlinked random partners with local communication treatment are included in Appendix I. Screen shots for the computer-mediated environment are included in Appendix II. 
Table 2. Mean system effort and predictions (in parentheses) for mean system effort by treatment

\begin{tabular}{lllll}
\hline & $\begin{array}{l}\text { No } \\
\text { Communication }\end{array}$ & $\begin{array}{l}\text { Global } \\
\text { Communication }\end{array}$ & $\begin{array}{l}\text { Local } \\
\text { Communication }\end{array}$ & $\begin{array}{l}\text { Global and Local } \\
\text { Communication }\end{array}$ \\
\hline No Output Sharing & $\begin{array}{l}284.22 \\
(288)\end{array}$ & $\begin{array}{l}262.70 \\
(<288)\end{array}$ & Not Applicable & Not Applicable \\
$\begin{array}{l}\text { Output Sharing with } \\
\text { Fixed Partners }\end{array}$ & $\begin{array}{l}150.40 \\
(156)\end{array}$ & $\begin{array}{l}164.93 \\
(156)\end{array}$ & $\begin{array}{l}227.92 \\
(234)\end{array}$ & $\begin{array}{l}210.82 \\
(234 \geq \text { effort } \geq 156)\end{array}$ \\
$\begin{array}{l}\text { Output Sharing with } \\
\text { Random Partners }\end{array}$ & $\begin{array}{l}152.77 \\
(156)\end{array}$ & $\begin{array}{l}169.05 \\
(156)\end{array}$ & $\begin{array}{l}186.57 \\
(234 \geq \text { effort } \geq 156)\end{array}$ & $\begin{array}{l}180.90 \\
(<\text { with only local } \\
\text { communication })\end{array}$ \\
$\begin{array}{l}\text { Output Sharing Not } \\
\text { Linked to Fixed } \\
\begin{array}{l}\text { Communication } \\
\text { Groups }\end{array}\end{array}$ & Not Applicable & Not Applicable & $\begin{array}{l}166.87 \\
(156)\end{array}$ & $\begin{array}{l}\text { 176.47 } \\
(156)\end{array}$ \\
\hline
\end{tabular}


Table 3. OLS regression for system effort with all factors and interactions

Factors and Interactions

Coefficient

Constant (CPR treatment with No Output Sharing and No Communication) 284.22***

Global Communication (G)

$-21.517^{*}$

$(10.445)$

Local Communication (L)

$77.517 * * *$

(5.076)

Fixed Partners (F)

$-133.817 * * *$

(4.433)

Random Partners (R)

$-131.450 * * *$

(10.431)

$-19.700^{*}$

(10.185)

$-31.633 * *$

(12.644)

$\mathrm{L} \& \mathrm{R}$

$-43.717 * * *$

(12.580)

G \& R

$37.800 * *$

(16.747)

G \& F

$36.050 * *$

(14.391)

G \& L \& R

9.683

(22.059)

$G \& L \& R \& U L$

15.267

(15.434)

Number of Observations

48

$\mathrm{R}$-squared

0.9102

Notes: Robust standard errors in parentheses. *** significant at $1 \%, * *$ significant at $5 \%, *$ significant at $10 \%$. The upper case letters in parentheses are identifiers for the different factors. Interaction terms are identified by factor identifiers separated by an ampersand (for example, $\mathrm{G} \& \mathrm{~L}$ is the interaction of global and local communication). The interactions L \& F, L \& UL, R \& UL, G \& UL, G \& L \& UL, G \& R \& UL, G \& L \& F and L \& R \& UL were dropped because of collinearity. 


\title{
APPENDICES TO BE MADE AVAILABLE ONLINE
}

\author{
APPENDIX I \\ INSTRUCTIONS (unlinked random partners and local communication treatment)
}

\section{Introduction}

You are about to participate in a project about economic decision-making. You will be asked to make decisions about the investment of resources between two activities, which will be referred to as Markets 1 and 2. The amount of money you will earn in today's session will depend on your investment in Market 1 and the sum of your and others' investments in Market 2. Your earnings will be paid to you privately, in cash, at the end of the session. The money for this project is provided by several funding agencies.

\section{The Environment}

During this session you and 11 other people will have to make decisions to invest resources in two markets. You will participate in 18 decision rounds, called periods. The first 3 periods will be for practice. The last 15 periods will determine your earnings at the end of the session.

At the start of the first round the 12 participants in the session will be divided into 3 groups of 4 people. The distribution of people to groups is random and none of the participants will know who is in his or her group. After each of the 18 periods is over, we will scramble the membership of all the groups, so that everyone is playing in a new group every period. Your earnings will depend upon the investment decisions that you make, the investment decisions that the members of your group make, and the investment decisions that the members of the other groups make. Your earnings in each round will be reported to you in Laboratory Dollars (L\$). These will be converted to Canadian Dollars (C\$) at the end of the session using the relationship $0.005 \times \mathrm{L} \$=\mathrm{C} \$$.

\section{The Markets}

At the beginning of each period you and each of the other participants will be given 28 tokens to invest. These tokens may be distributed in any way you wish between the two markets. Each period you will decide how many tokens to invest in Market 2. Whatever you do not invest in Market 2 will be automatically invested in Market 1.

Each token you invest in Market 1 yields a fixed return of L\$3.25. This return per token is independent of the amount you invest or others invest in Market 1. Your return from Market 2 depends on the total investment in this market by all participants in the session.

Although you keep all of your return from Market 1, you and the rest of your group will pool your returns from Market 2 and share them equally. Thus your payoff from Market 1 equals your return from Market 1 and your payoff from Market 2 equals your share of your groups' returns from Market 2. Your total payoff for the period is the sum of your payoffs in the two markets.

\section{Numerical Example}

In today's session there will be 3 groups of 4 participants. Each participant will have an endowment of 28 tokens to distribute between investments in Market 1 and Market 2.

Suppose you invest 11 tokens in Market 2. Assume that each of the other members of your group invests 
19 tokens. Assume that each of the other participants (not in your group) invests 17 tokens in Market 2. Here is how your payoffs in Market 1 and Market 2 are calculated:

You invest 11 tokens in Market 2, leaving 17 tokens to be invested in Market 1.

The total investment in Market 2 by the other members of your group is $3 \times 19=57$ tokens.

The total investment in Market 2 by the participants not in your group is $8 \times 17=136$ tokens.

The total investment in Market 2 by all participants is $11+57+136=204$ tokens.

The Market 2 Total Return Table shows the total and average return per token for a number of values of total investment in Market 2. If 204 tokens are invested in Market 2 the total return will be L\$2728.50. The average return per token is $\mathrm{L} \$ 13.375$.

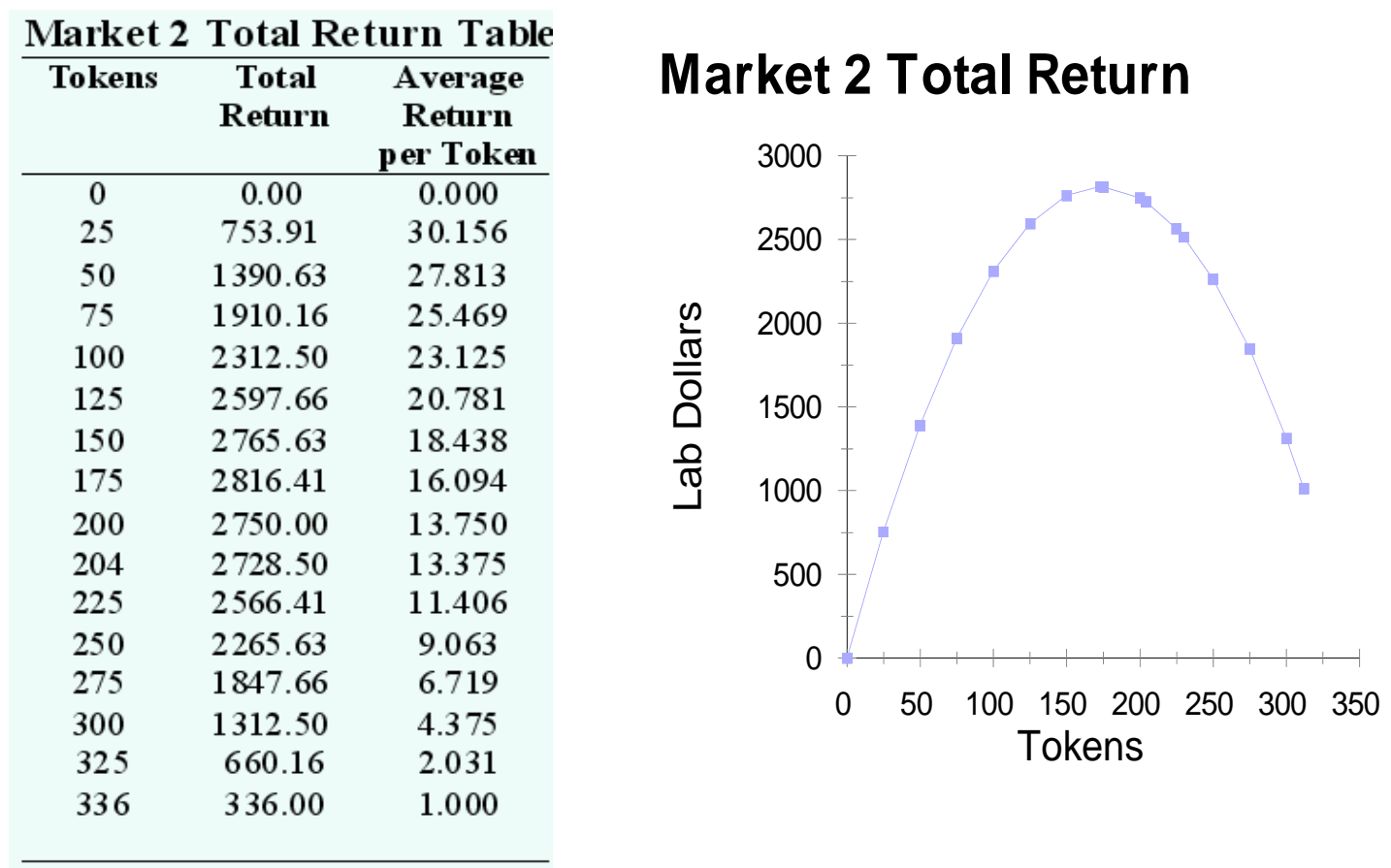

Your return from the 11 tokens you invested in Market 2 is $\mathrm{L} \$ 13.375 \times 11=\mathrm{L} \$ 147.125$. The total return from the 19 tokens invested by each of the other members of your group is $\mathrm{L} \$ 13.375 \times 19=\mathrm{L} \$ 254.125$. Therefore the total return to your group is $\mathrm{L} \$ 909.50$. Since you share this return equally, your total payoff from Market 2 is $\mathrm{L} \$ 909.50 / 4=\mathrm{L} \$ 227.375$.

The constant return in Market 1 is L $\$ 3.25$ per token. Therefore the return from the 17 tokens you invested in Market 1 is $3.25 \times 17=\mathrm{L} \$ 55.25$.

Your total payoff from both markets combined is $\mathrm{L} \$ 55.25+\mathrm{L} \$ 227.38=\mathrm{L} \$ 282.63$.

Each of your group partners total payoff, on the other hand, is $\mathrm{L} \$ 227.38+9 \times \mathrm{L} \$ 3.25=\mathrm{L} \$ 256.63$.

To simplify these calculations, the computer will show you an abbreviated Payoff Table for Market 2 and a Payoff Wizard which will calculate the exact payoff for any combination of your investment, the average investment by others that are in your group, and the average investment by others that are not in your 
group. The abbreviated Payoff Table will be similar to the Payoff Table for Market 2 shown below.

\begin{tabular}{|c|c|c|c|c|c|c|c||}
\hline \multicolumn{7}{|c|}{$\begin{array}{c}\text { Payoff Table for Market 2: Your Payoff Only When There are 3 Groups } \\
\text { with 4 Members in Each Group }\end{array}$} \\
\hline \hline $\begin{array}{c}\text { Average Investment of } \\
\text { Tokens in Market 2 by } \\
\text { Members of Your Group }\end{array}$ & $\mathbf{0}$ & $\mathbf{6}$ & $\mathbf{1 1}$ & $\mathbf{1 7}$ & $\mathbf{2 2}$ & $\mathbf{2 8}$ \\
\hline $\begin{array}{c}\text { Average } \\
\text { Investment } \\
\text { of Tokens in } \\
\text { Market 2 by }\end{array}$ & $\mathbf{0}$ & 0 & 181.50 & 312.13 & 444.13 & 533.50 & 616.00 \\
\cline { 2 - 10 } \begin{tabular}{c} 
All \\
Participants \\
Other Than \\
Those in \\
\cline { 2 - 10 }
\end{tabular} & $\mathbf{6}$ & 0 & 154.50 & 262.63 & 367.63 & 434.50 & 490.00 \\
\cline { 2 - 9 } Your Group & $\mathbf{1 1}$ & 0 & 132.00 & 221.38 & 303.88 & 352.00 & 385.00 \\
\hline
\end{tabular}

The payoff based upon the numbers given in the previous section can be easily calculated from this Payoff Table. Since your group invested $11+57=68$ tokens, the average investment by people in your group is $68 / 4=17$ tokens. Locate the column headed "17". Since the other participants not in your group each invested 17 on average, locate the row labeled "17". The number at the intersection of these rows and columns (227.38) is your share of your group's return from Market 2. Adding L\$55.25 (your payoff from Market 1) to this gives your total payoff of L\$282.63.

\section{Practice Periods}

To let you learn more about the environment we are going to run 3 practice periods. The results from these periods will not contribute to your final earnings. If you have any questions during these 3 periods, please raise your hand and we will answer them.

After the 3 periods are over, we will scramble members of the groups and begin the 15 periods which contribute to your earnings.

(Monitor starts the session)

Please examine your computer screens. In the upper right hand frame you will find a Payoff Table like the one in your instructions. Locate the cell showing your Market 2 payoff if you invest 11 tokens, the others in your group invest 19 tokens and the people not in your group invest 17 tokens each. To find the cell you must calculate the average investment made by all of the members of your group (11 by you and 19 by each of the other 3 is 68 tokens; divided by 4 equals 17 tokens). Under these hypothetical conditions, your payoff from Market 2 would be L $\$ 227.38$.

Please click on this cell. Now look at the Wizard at the upper left hand side of the screen. Note that the numbers from the Payoff Table have been entered into the Wizard. Your investment is identified as 17 tokens, the average investment of the others in your group is identified as 17 tokens, and the average investment of others not in your group is identified as 17 tokens. Note the displayed payoff from Market 2 is L\$227.38 and your displayed Total Payoff is L\$263.13.

Now use the spin-edit box to change your investment to 11 tokens and the average investment by others in your group to 19 tokens. Note that your payoff from Market 2 has not changed, but your Total Payoff has 
increased to L $\$ 282.63$. This total payoff is identical to the payoff you calculated in the previous example, in which your group average investment was 17 , but you invested 11 tokens, while each of the others in your group invested 19 tokens.

You can calculate the payoff for any other combinations of investments by altering the numbers in the spin edit box.

You make your decision by filling in the form at the lower left of your screen. Notice that the spin-edit box on this form shows the last value you entered into the Wizard. You can accept this value or change it any way you please. After you have entered your desired investment decision, push the Press Here When Done button.

We are now ready to start the practice sessions. Please make your decisions and submit them.

(after results are shown)

The computer screens are now showing the results of the period. When you are finished examining them, please press Done

(after screens change)

You are now ready to start the second practice period. Notice the results from last period are shown on the history page on the right hand side of your screen. Remember that the groups have all been scrambled and you will be in a new group every period. Please make your decisions and submit them as before.

(after results are shown)

The results of the second practice period are now being shown. Please examine them and then proceed to the third practice period.

(after third period begins)

This is the third and final practice period. Please make your decisions and submit them as before. When the results of the third session appear, do not press the Done until you have read the remaining instructions.

(after the results appear)

\section{Communication}

Prior to the first paid period, you will be able to send messages to other members in your group. Everyone in your group will see the messages you send. To see how, please click now on the messenger tab in the lower portion of your screen. The messenger window will open. Then click on the lower (white) part of the box and type "hello". Please everyone type "hello" now. Then click the 'Send' button, so that others in your group can read your message. If you look at the messenger window you will see how many seconds remain for exchanging messages. The messenger window will be active for four minutes before the first paid period.

After the exchange of messages you will make investment decisions. Although you will make investment decision in a new group each period, the composition of your communication group is the same across all periods. More specifically, before making decisions, you will always be able to send messages to the same 
group as you communicate with in the first paid period.

Prior to the second and third decision periods, this is set at three minutes. Prior to the fourth round this is set at two minutes and from the fifth through the fifteenth rounds, communication is limited to one minute. Now please switch to the main window by clicking on the background.

Although we will record the messages your group sends to each other, only the people in your group will see them. In sending messages, you should follow two basic rules: (1) Be civil to one another and do not use profanities, and (2) Do not identify yourself in any manner. The communication channel is intended to discuss your choices and should be used that way.

Please do not close any window at any time because that will cause delays and problems with the software.

\section{Paid Periods}

We are now about to begin the paid portion of the session. We will scramble the membership of all the groups so that your group will consist of a completely new set of 4 people in each of the next 15 periods.

If you have any questions, please ask them now.

Please examine the results of the third practice period and press Done. When everyone has done this, the first paid period will begin automatically. Please continue to follow the computer prompts until the end of the session. 


\section{APPENDIX II}

\section{SCREEN SHOTS}

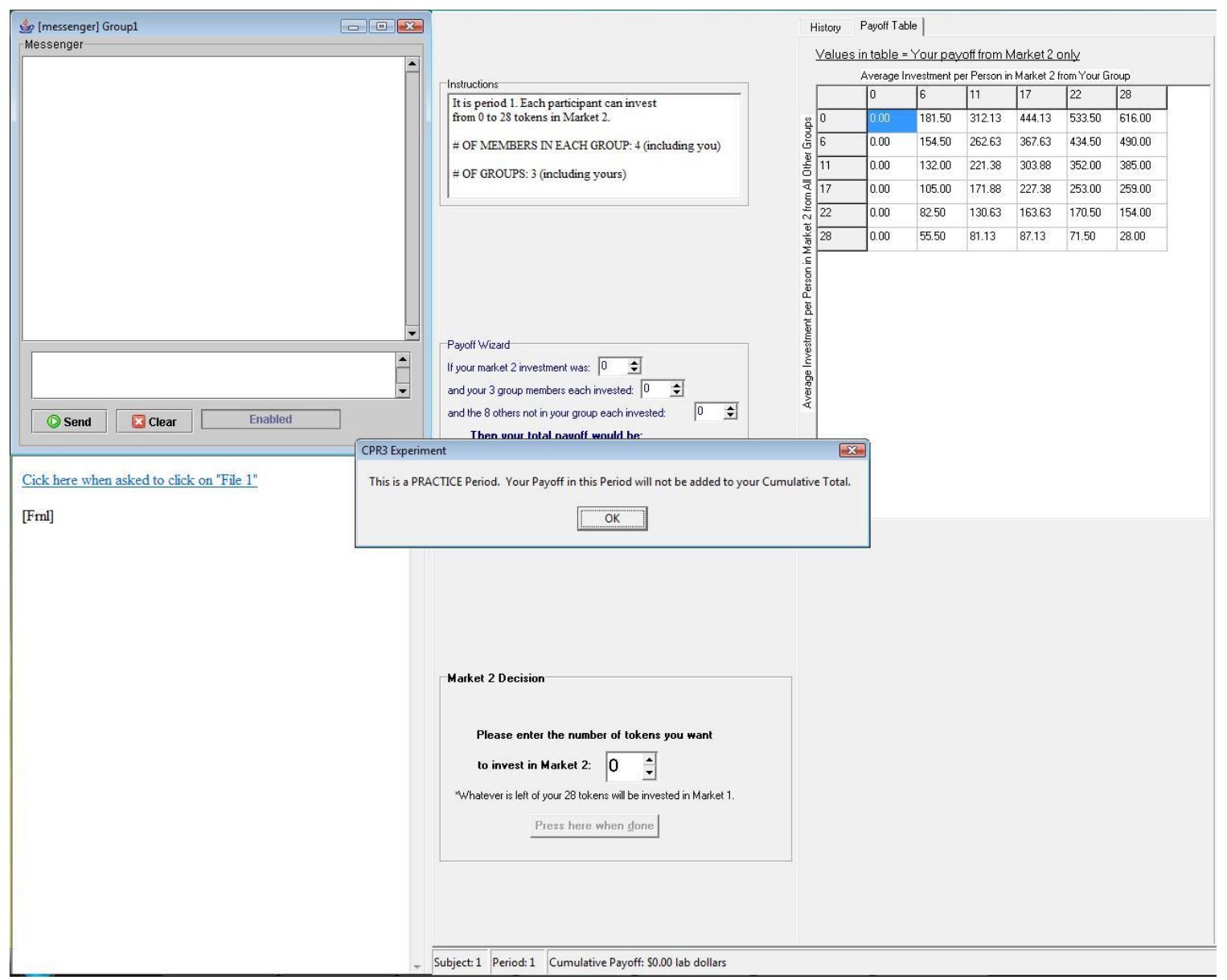

Figure II.1 Decision Screen 


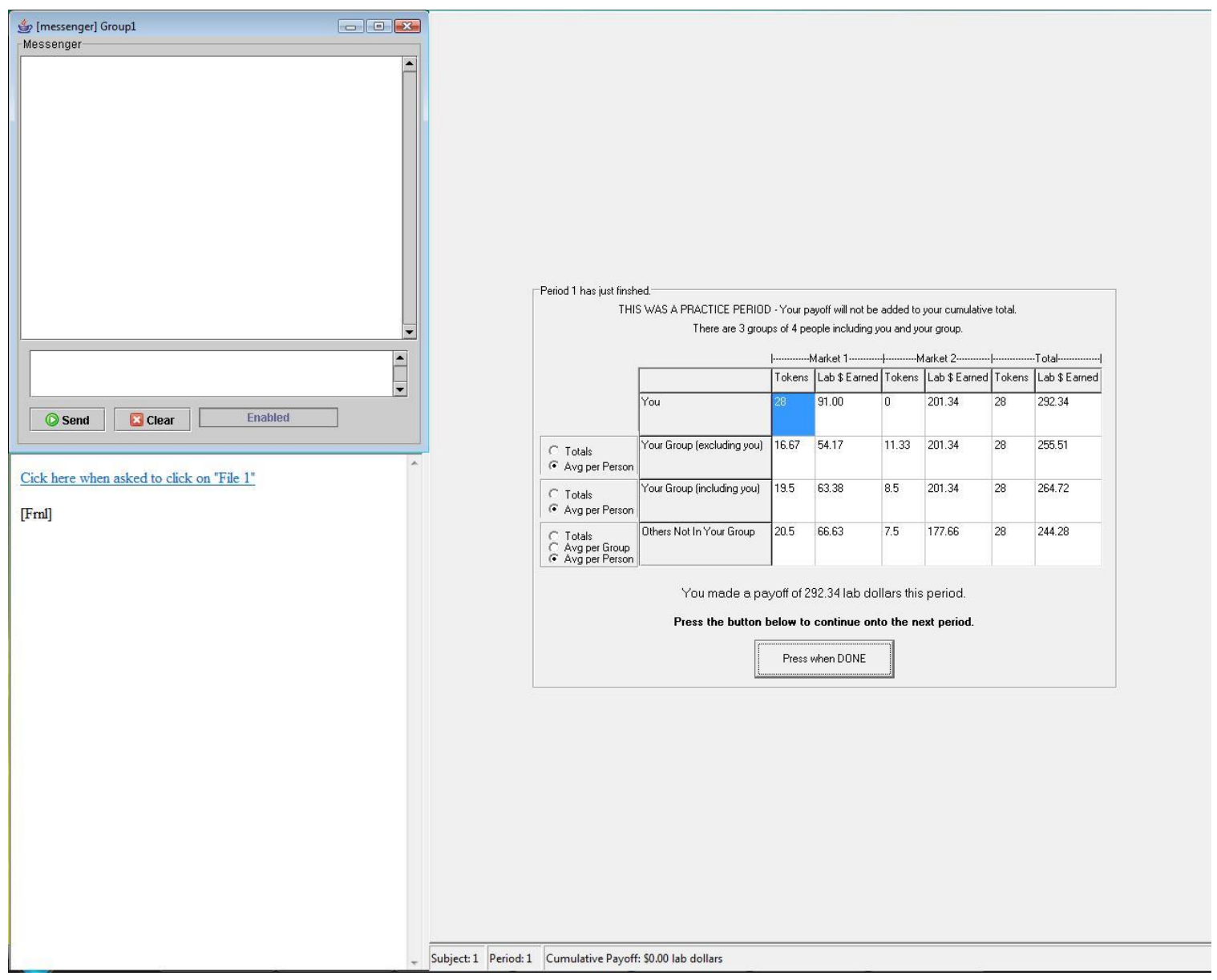

Figure II.2 Outcome Screen 


\section{APPENDIX III}

\section{1. Equilibrium for CPR Environment when Individuals in Groups Attempt to Maximize Individual Profits when Output Sharing is Used as a Management Instrument}

Total output as a function of "effort" of all individuals using the CPR $(X)$ is

$Y=32.5 X-0.09375 X^{2}$

Individual Profit as a function of individual effort $(x)$, the effort by members of the individual's group $\left(X_{g}\right)$ and the effort by all individuals using the CPR $(X)$ is

$\pi=3.25(28-x)+\frac{1}{n} \frac{X_{g}}{X} Y$

where $n$ is the number of people in the individual's group. If $n=1$ then $X_{g}=x$.

Differentiating $\pi$ with respect to $x$ and setting this equal to zero yields

$$
-3.25+3.25 \frac{1}{n}-0.09375 \frac{1}{n}\left(X+X_{g}\right)=0 .
$$

This reduces to

$$
X+X_{g}=(32.5-3.25 n) \frac{1}{0.09375} \text {. }
$$

There is an equation like this one for each member of each group. When the groups have more than one member, the equations for all of the members in any particular group are identical. This results in three unique equations of the form

$$
X+{ }^{m} X_{g}=\frac{(32.5-3.25 n)}{0.09375}
$$

where $m$ is the group identifier.

In the case of three four-person groups, there would be three equations with three unknowns, ${ }^{1} X_{g},{ }^{2} X_{g}$, and ${ }^{3} X_{g}$. The solution will be

$$
{ }^{m} X_{g}=\frac{32.5-13}{0.09375} \times \frac{1}{4}=52 .
$$

The important result is that there is not a unique equilibrium quantity for the individual. The equilibrium condition requires that the sum of the contributions of the individuals in a group equals a unique value. There is a unique group Nash equilibrium allocation of effort to appropriation from the common pool. In this case, the unique group Nash equilibrium amount of effort is 52. The system effort is 156 . 


\section{2. Equilibrium for CPR Environment when Individuals in Groups Attempt to Maximize Group Profits when Output Sharing is Used as a Management Instrument}

Individual Profit as a function of individual effort $(x)$, the effort by members of the individual's group $\left(X_{g}\right)$ and the effort by all individuals using the CPR $(X)$ is

$\pi=3.25(28-x)+\frac{1}{n} \frac{X_{g}}{X} Y$

Profit for the group is

$\pi_{g}=3.25 \times 28 n-3.25 X_{g}+32.5 X_{g}-0.09375 X X_{g}$.

Differentiating $\pi_{g}$ with respect to $X_{g}$ and setting this equal to zero yields

$X+X_{g}=\frac{29.25}{0.09375}$

When there are twelve appropriators from the common pool and $n=4$, there are three output-sharing groups and $\mathrm{X}=3 X_{g}$, therefore

$X_{g}=78$.

The Nash equilibria in the situations described above result in the following values. The important result is that there is not a unique equilibrium quantity for the individual. The equilibrium condition requires that the sum of the contributions of the individuals in a group equals a unique value. There is a unique group Nash equilibrium allocation of effort to appropriation from the common pool. In this case the unique group Nash equilibrium amount of effort is 78. The system effort is 234 . 


\section{3. A Coalition-Proof Equilibrium for a CPR Environment with three Output-Sharing Groups, Local communication and Global communication}

We can also derive a coalition proof equilibrium for three output-sharing groups that communicate locally as well as globally (our treatment FFC). In this environment there are only three possible configurations of groups. There can be a coalition of three groups, a coalition of two groups or no coalition. If a coalition of three groups forms and each group exerts 52 units of effort, there will be no incentive for one of the groups to leave the coalition. In this case the socially efficient outcome of 156 is also the coalitionproof equilibrium as the following table indicates:

\begin{tabular}{|c|c|c|c|c|c|c|c|c|c|c|c|}
\hline \multicolumn{3}{|c|}{ Results with $n=3 ; e=112$} & \multicolumn{9}{|c|}{$\begin{array}{l}\text { There is a Coalition Proof Equilibrium with a Coalition of } 3 \text { with Global and/or Local communication } \\
\text { (average individual payoffs are one-quarter of group payoffs) }\end{array}$} \\
\hline & $\begin{array}{l}\text { Total } \\
\text { Effort }\end{array}$ & $\begin{array}{l}\text { Total } \\
\text { Yield }\end{array}$ & $\begin{array}{l}\text { Coalition } \\
\text { Yield }\end{array}$ & $\begin{array}{l}\text { Coalition } \\
\text { Outside }\end{array}$ & $\begin{array}{l}\text { Coalition } \\
\text { Total }\end{array}$ & $\begin{array}{l}\text { Follower } \\
\text { Yield }\end{array}$ & $\begin{array}{l}\text { Follower } \\
\text { Outside }\end{array}$ & $\begin{array}{l}\text { Follower } \\
\text { Total }\end{array}$ & $\begin{array}{l}\text { Coalition } \\
\text { Effort }\end{array}$ & $\begin{array}{l}\text { Follower } \\
\text { Effort }\end{array}$ & Total \\
\hline $\begin{array}{c}\text { Coalition } \\
1 \mathrm{~L}\end{array}$ & 245.33 & 2330.67 & 1064.00 & 0.00 & 1064.00 & 633.33 & 147.33 & 780.67 & 112.00 & 66.67 & 245.33 \\
\hline $\begin{array}{c}\text { Coalition } \\
2 \mathrm{~L}\end{array}$ & 234.00 & 2471.63 & 823.88 & 110.50 & 934.38 & 823.88 & 110.50 & 934.38 & 78.00 & 78.00 & 234.00 \\
\hline $\begin{array}{c}\text { Coalition } \\
1 \mathrm{~N}\end{array}$ & 234.00 & 2471.63 & 823.88 & 110.50 & 934.38 & 823.88 & 110.50 & 934.38 & 78.00 & 78.00 & 234.00 \\
\hline $\begin{array}{c}\text { Coalition } \\
2 \mathrm{~N}\end{array}$ & 234.00 & 2471.63 & 823.88 & 110.50 & 934.38 & 823.88 & 110.50 & 934.38 & 78.00 & 78.00 & 234.00 \\
\hline $\begin{array}{c}\text { Coalition } \\
3\end{array}$ & 156.00 & 2788.50 & 929.50 & 195.00 & 1124.50 & 0.00 & 0.00 & 0.00 & 52.00 & 52.00 & 156.00 \\
\hline Optimal & 156.00 & 2788.50 & 232.38 & 48.75 & 281.13 & 232.38 & 48.75 & 281.13 & 13.00 & 13.00 & 156.00 \\
\hline \multicolumn{12}{|l|}{ Notes: } \\
\hline \multicolumn{12}{|c|}{$\begin{array}{l}\text { lotes: } \\
\text { Coalition 1L: Outcome with } 1 \text { group as leader and } 2 \text { followers; this is a corner solution; this is not coalition proof. }\end{array}$} \\
\hline \multicolumn{12}{|c|}{ Coalition 2L: Outcome with a 2-group coalition as leader and 1 follower; this is an equilibrium, but it is not coalition proof. } \\
\hline \multicolumn{12}{|c|}{$\begin{array}{l}\text { Coalition } 1 \mathrm{~N} \text { : Nash equilibrium with three 1-group coalitions; this is coalition proof to marginal changes of coalition size; this is the group profit-maximization } \\
\text { outcome. }\end{array}$} \\
\hline \multirow{2}{*}{\multicolumn{12}{|c|}{ Coalition 2N: Nash outcome given one 2-group coalition and one 1-group coalition: this is not coalition proof. }} \\
\hline \multirow{2}{*}{\multicolumn{12}{|c|}{$\begin{array}{l}\text { Coalition 3: Nash outcome given one 3-group coalition; this is a coalition-proof equilibrium } \\
\text { Optimal: Payoffs in this line are the average individual payoffs. }\end{array}$}} \\
\hline & & & & & & & & & & & \\
\hline \multicolumn{12}{|c|}{ "Yield" is the return from the CPR to the coalition or to the follower. } \\
\hline
\end{tabular}

For a CPR environment with three output-sharing groups that cannot communicate locally, but can communicate globally, the socially efficient outcome of 156 units of effort is the coalition-proof equilibrium. 


\section{APPENDIX IV}

Table V.1. p-values for pairwise comparisons of environmental variables for F-tests from system effort OLS regression with robust standard errors

\begin{tabular}{|l|l|l|l|l|l|l|l|l|l|l|l|}
\hline & F & R & FF & RR & RF & BC & FC & RC & FFC & RRC & RFC \\
\hline B & $\mathbf{0 . 0 0 0}$ & $\mathbf{0 . 0 0 0}$ & $\mathbf{0 . 0 0 0}$ & $\mathbf{0 . 0 0 0}$ & $\mathbf{0 . 0 0 0}$ & $\mathbf{0 . 0 4 7}$ & $\mathbf{0 . 0 0 0}$ & $\mathbf{0 . 0 0 0}$ & $\mathbf{0 . 0 0 0}$ & $\mathbf{0 . 0 0 0}$ & $\mathbf{0 . 0 0 0}$ \\
\hline F & & 0.827 & $\mathbf{0 . 0 0 0}$ & $\mathbf{0 . 0 0 0}$ & 0.085 & $\mathbf{0 . 0 0 0}$ & 0.150 & $\mathbf{0 . 0 4 5}$ & $\mathbf{0 . 0 0 0}$ & $\mathbf{0 . 0 1 3}$ & $\mathbf{0 . 0 0 0}$ \\
\hline R & & & $\mathbf{0 . 0 0 0}$ & $\mathbf{0 . 0 0 5}$ & 0.294 & $\mathbf{0 . 0 0 0}$ & 0.378 & 0.220 & $\mathbf{0 . 0 0 0}$ & 0.069 & $\mathbf{0 . 0 3 0}$ \\
\hline FF & & & & $\mathbf{0 . 0 0 0}$ & $\mathbf{0 . 0 0 0}$ & $\mathbf{0 . 0 0 2}$ & $\mathbf{0 . 0 0 0}$ & $\mathbf{0 . 0 0 0}$ & $\mathbf{0 . 0 3 5}$ & $\mathbf{0 . 0 0 0}$ & $\mathbf{0 . 0 0 0}$ \\
\hline RR & & & & & 0.059 & $\mathbf{0 . 0 0 0}$ & $\mathbf{0 . 0 4 9}$ & 0.084 & $\mathbf{0 . 0 0 9}$ & 0.652 & 0.110 \\
\hline RF & & & & & & $\mathbf{0 . 0 0 0}$ & 0.879 & 0.856 & $\mathbf{0 . 0 0 0}$ & 0.327 & 0.297 \\
\hline BC & & & & & & & $\mathbf{0 . 0 0 0}$ & $\mathbf{0 . 0 0 0}$ & $\mathbf{0 . 0 0 0}$ & $\mathbf{0 . 0 0 0}$ & $\mathbf{0 . 0 0 0}$ \\
\hline FC & & & & & & & & 0.741 & $\mathbf{0 . 0 0 0}$ & 0.276 & 0.240 \\
\hline RC & & & & & & & & & $\mathbf{0 . 0 0 0}$ & 0.400 & 0.404 \\
\hline FFC & & & & & & & & & & $\mathbf{0 . 0 2 9}$ & $\mathbf{0 . 0 0 0}$ \\
\hline RRC & & & & & & & & & & & 0.704 \\
\hline
\end{tabular}

Note: The p-values are for two-tailed F-tests based on pairwise comparisons of environments reported in Table 2. Significantly different treatments are identified by bolded $\mathrm{p}$-values.

B: no output sharing, no communication (baseline treatment)

F: output sharing with fixed partners, no communication

$\mathrm{R}$ : output sharing with random partners, no communication

FF: output sharing with fixed partners, local communication

RR: output sharing with random partners, local communication

RF: output sharing with random partners, unlinked local communication

BC: baseline with global communication

FC: output sharing with fixed partners, global communication

RC: output sharing with random partners, global communication

FFC: output sharing with fixed partners, local \& global communication

RRC: output sharing with random partners, local \& global communication

RFC: output sharing with random partners, unlinked local communication \& global communication 